\title{
Analyzing the museum experience through the lens of Instagram posts
}

\author{
Bo-A Rhee, College of Art \& Technology, Chung-Ang University, Republic of Korea \\ Federico Pianzola, a research fellow at University of Milan-Bicocca (Italy) and Sogang \\ University (South Korea) E-mail: federico.pianzola@unimib.it
}

Gang-Ta Choi, a graduate student at Department of Computer Science \& Engineering, ChungAng University, Republic of Korea. E-mail: cminor_delf@naver.com

Corresponding author: Bo-A Rhee: boa.rhee@gmail.com

* This research is an outcome of the "Leaders in INdustry-university Cooperation +" Project (20201232), supported by the Ministry of Education and National Research Foundation of Korea (2020). It was also supported by the Chung-Ang University Research Grants in 2019.

\begin{abstract}
The purpose of this study is to examine visitors' Instagram posts through a combination of quantitative methodology to cast light on museum experiences. To analyze a large quantity of Instagram data, we used computer vision and semantic analysis. The results of hashtag analysis showed that informative hashtags were the most prominent for all museums. It is notable that the geo-related hashtags such as exhibition venue and local information accounted for a significant portion of the total data. Little to no evidence of viewing experience or emotional response can be derived from the results of hashtag analysis. In the image analysis of Instagram post, art exhibition, artifact and architecture were dominant, but the space within and around museums is also relevant. Thus, Instagram images can be an important component for understanding what is occurring within and around the museum when people move to take photographs and share these experiences on Instagram. This research offers a method for image analysis easily replicable by museums and insight about how to interpret the results for planning activities of audience development.
\end{abstract}

Keywords: Instagram, Museums, Visitors Pictures, Digital Humanities, Computer Vision

\section{INTRODUCTION}

The pervasiveness of social media has recently changed the way people interact with each other in hyper-connected societies (Dudareva 2014; Phan and Macias 2018), marking a fundamental shift in contemporary culture: some people carefully choose locations to visit specifically with the aim of sharing their cultural experiences on social media. Social media have had a profound impact on cultural institutions and their visitors by influencing not only marketing campaigns but also the creation, appreciation, and curation of art (Sokolowsky 2017). In this new 
landscape, a crucial question emerges - what does this socio-cultural change mean for museums and museum visitors?

Museums are visual by nature. Exhibitions present in a carefully curated way unique and attractive objects. During the visit, visitors learn specific information about the subject matter, but also create their own associations and narratives about the exhibit, which can later converge in Instagram posts. In particular, photos on Social Network Service (hereafter SNS) are no longer just personal images that evoke memories (Chlebus-Grudzień 2018): they allow visitors to create a clear visual narration of concrete aspects and objects as well as abstract values with which the audience can identify (Zingone 2019). These images function as a device for registering relationships and experiences from material cultural spaces to the databases of social media (Carah 2014, 4). In this perspective, social media can be an incredible tool for generating excitement and expectation about an exhibition and they have often become the driving force of visits to museums (Stylianou-Lambert 2017).

With the growing influence of SNS globally, a number of museums have created an online presence on social media to promote their programs and activities, to facilitate participatory cultural experiences, and to enable visitors to engage in a dialogue with them (Russo et al. 2009). The relationships between social media and museums, and between social media and visitors, have become a very relevant topic in the museum community. In an effort to share good practices, the International Council of Museums has recently published 'Social Media Guidelines for ICOM Committees (2019).' This bidirectional discourse on social media can bridge the digital-physical gap, with museums expecting social media to foster steady and significant changes in the role of visitors and relationships between visitors and museums (Koke and Ryan 2017): social media followers may turn into visitors, visitors may turn into members, members may turn into donors, and donors may turn into outspoken advocates for a museum (Gelles 2017). From a museum perspective, visitors can be transformed from passive observers into active participants and even online marketers (Villaespesa 2013; Holdgaard and Klastrup 2014) through documenting, re-curating, sharing and communicating their experience. In addition, social media enables the audiences as content creators to interact with curators as facilitators directly (Kelly 2009).

Among the various SNS available, Instagram is the most visual-centric, since its main use consists in uploading pictures and applying various filters in order to obtain the desired appearance. Two other widespread SNS in which visuals are quite important are Facebook and TikTok. The former is a generalist SNS on which pictures are shared as part of various kind of posts and it is difficult to collect content referring to a specific museum. TikTok is a newer platform for sharing short funny videos, rarely used to document visits to art venues (Omar and Dequan 2020). For these reasons, focusing on Instagram seemed the most appropriate choice for our research, also given the wide availability of useful user-generated metadata in the forms of hashtags.

The purpose of this study is twofold: first, to provide insight into the current engagement of museum visitors utilizing Instagram posts; second, to design a methodology that can help museums to autonomously analyze Instagram posts. To date, a little attention has been paid to the meanings and implications generated from Instagram posts, mainly due to the lack of ready-to-use tools to collect data, and existing studies do not cover extensive amount of user-generated content. This article attempts to bridge the gap by analyzing the practical examples of Instagram posts related to museums through a transdisciplinary approach and use of digital methods in the age of Museum 3.0 (Rhee 2020). One of the criteria used in the selection of the digital tools employed is to allow the application of our procedures by museums 
without requiring advanced knowledge of computer vision or machine learning techniques. We wanted museums to be able to easily use the described methods integrating them in their visitors' analysis.

\section{INSTAGRAM AND INSTAGRAMMABLE EXHIBITIONS}

According to statistics published by OMNICORE (2020), Instagram reached one billion monthly-active-user. Instagram, a portmanteau of Instamatic and telegram, is a popular social networking service characterized by a type of informal classification system called "folksonomy," that is a user-generated categorization of social media content through hashtags (Malik 2019, 11). Hashtags on Instagram can describe the content of the image, but can as well represent subjective opinions, feelings, places, or a variety of expressions pertaining to colloquial language (Ibba et al. 2015). They influence the discovery of new products and services, purchasing decisions and promotion of brands through electronic word of mouth.

Thanks to the encounter of museums and Instagram, a new phenomenon emerged recently: "Instagrammable exhibitions." According to the Collins Dictionary, "Instagrammable" is a relatively new word and it means "worthy of being posted on Instagram." When accompanied by "exhibition," the term refers to Instagram-friendly exhibitions that are inherently different from traditional exhibitions. From the Museum of Ice cream in San Francisco to the Colorful Museum in Seoul, these splendid pop-up exhibits are designed for the primary purpose of fostering the sharing of pictures on Instagram. In particular, Instagrammable exhibitions cater to the preferences of Generation $Z$ highly connected and networked lifestyle (Prensky 2001). Based on a survey we did among Generation Z (born 19952010 circa) about Instagram use in relation to museums, the majority $(91.3 \%)$ uses the app to search information about exhibitions and $70.4 \%$ to discover other visitors' experiences. Participants said they highly depend on SNS reviews for choosing what exhibitions to visit and more than a half of them (61.9\%) agree that the information found on Instagram is useful (Kang et al. 2020).

In recent years, we have seen a similar phenomenon in traditional art museums, which are getting significant publicity from Instagram posts, whether or not they intend to exploit social media communication. As hashtags have become a semantic tool and a potential drive for museums, major art exhibitions come pre-branded with hashtags, and most major art events tend to spawn their own: exhibitions that generated many Instagram posts are Leandro Erlich: Seeing and Believing (Mori Art Museum, 2018), Yayoi Kusama: Infinity Mirrors Mirrors (the Seattle Art Museum, 2018) and Do Ho Suh: Almost Home (Smithsonian American Art Museum, 2018). Among these, nearly 160,000 people experienced the Seattle Art Museum's recordbreaking Kusama exhibition and posted around 34,000 snapshots from it on their Instagram accounts (McDonough 2017). On the other hands, also traditional art museums sometimes create social media events to facilitate participatory cultural experience: for example, the Orsay Museum has recently invited the illustrator Jean-Philippe Delhomme to collaborate to the management of their Instagram account by creating a different drawing each week, depicting an artist as a contemporary social media user.

Another related phenomenon is that of selfies, which are not just a representation of a person, sometimes together with objects. They are rather a social form of photography aiming at communicating with others. The selfie "says not only 'see this, here, now,' but also 'see me showing you me.' It points to the performance of a communicative action rather than to an object, and is a trace of that performance" (Frosh 2015). In particular, museums provide a stage for "identity work that offers an opportunity for the selfie to be used not only for superficial 
performances but also in the pursuit of more profound self-reflection and its communication". Museum selfies can take various forms and communicate different aspects of "people's everincomplete identity:" they can be art interactions, blending into art, mirror selfies, silly/clever selfies, contemplative selfies, and iconic selfies (Kozinets et al. 2017).

\section{PREVIOUS RESEARCH ON INSTAGRAM REGARDING MUSEUM EXPERIENCES}

Researchers have started investigating the impact of photo-sharing and self-presentation on Instagram (Pittman and Reich 2016). The analysis of emotions expressed in social media texts has become a popular research topic, also leading to the identification of a typology of hashtags: informative (i.e. branded or product hashtags, location hashtags, lifestyle hashtags, subject hashtags and community hashtags), participatory (i.e. events or advertising hashtags, campaign hashtags, and public relations hashtags), and for exposure (i.e. most-liked hashtags, niche hashtags, stories hashtags, and holiday hashtags) (Kim 2016; Oh et al. 2016; Rauschnabel et al. 2019; Park et al. 2019). Other researchers have harvested hashtag data and patterns to analyze positive and negative emotions for specific topics (Davidov et al. 2010; Conover, et al. 2011; Villaespesa 2013; Qadir and Riloff 2014; Syed 2015; Zafiropoulos et al. 2015; Tartir and Abdul-Nabi 2017; Hasan et al. 2018; Păvăloaia et al. 2019). To sum up, hashtags are not just a means to structure user-generated content on social media, but they create a virtual location around which conversations emerge (Rauschnabel et al. 2019).

Instagram research in the context of museums is an emergent field but several insights can be drawn from studies conducted so far. Social media are being leveraged as a communication tool for fostering the dialogue between museums and online communities (Capriotti and Kuklinski 2012). Visitors use Instagram to combine their museum experiences with their own narratives in a process of self-image construction, remembrance, memory, place-making, aesthetic inspiration, and play (Weilenmann et al. 2013; Budge and Burness 2018; Budge 2018; Suess 2018; Chlebus-Grudzień 2018; Villaespesa and Wowkowych 2020). Qualitative research conducted at the Smithsonian National Portrait Gallery suggests that visitors regarded photos as tools for enhancing museum experiences, providing entry points to exhibitions, and creating more interactive experiences (Stylianou-Lambert 2017). Another case study of one Australian art gallery showed that Instagram posts facilitates the promotion and recommendation of the exhibition (Suess 2014). Notably, a research on science museums' Instagram posts revealed a recurrent lack of scientific images and science-related hashtags, and that nearly a third of the posts contained no obviously science-related content at all (Jarreau et al. 2019). Therefore, how visitors re-elaborate their museums experience when using Instagram is still an open issue.

While museums use different sets of metrics to evaluate their social media activities and better understand their online audiences, very few examples exist of how to analyze a large quantity of Instagram data. One example is a research project at the Australian Museum of Contemporary Art (Budge and Burness 2018). To understand visitors' engagement with objects, 390 images were collected and categorized through a semi-automated method into: object only, people and objects, people only, and others. The results showed that visitors primarily use Instagram to engage with objects rather than taking selfies (Budge and Burness 2018; Budge 2017; Villaespesa and Wowkowych 2020). In an analysis of the official profiles of Louvre Museum and Metropolitan Museums of Art, 30 Instagram posts for each museum have been categorized into: spaces, objects, and people as macro categories. In the case of Louvre Museum, the space category was dominant, while in the case of the Metropolitan Museum of Art the object category was more than five times higher than the space category (Zingone 2019). 
To sum up previous research results: space, object, and people are suitable categories for classifying Instagram data. We combined this insight with automated computational tools like computer vision and semantic analysis in order to manage a bigger dataset and improve the reliability and accuracy of the results.

Prior to collecting Instagram data in 2019, our first author participated in examining Instagram hashtags for the Korean exhibitions: Paper Present (2017), Monet's Impressionism Exhibition (2018), Van Gogh Inside (2016) and Drawn by the Wind: Shin Yook Bok \& Jeong Seon (2017) (Park et. al 2019). Since the results are available in Korean only but are an important premise to the present research, we briefly summarize them here. After collecting more than 80,000 hashtags from user-generated Instagram posts that included the exhibition title - \#paperpresent (17,292), \#monetsimpressionism (52,717), \#vangoghinside $(9,733)$ and \#drawnbythewind $(5,311)$ - the hashtags were manually classified into the typology presented in previous studies along with sub-categories: informative (i.e. exhibition title, exhibition venue, local information and general art-related hashtags), participatory, and exposure (e.g. \#selfie and \#picoftheday); and other hashtags (e.g. \#weekend and \#date). Since neither the museums nor the users started any kind of trend related to the exhibitions, we did not find any participatory hashtag.

The results showed that informative hashtags were the most prominent for all exhibitions: Paper present (86.5\%), Monet's Impressionism Exhibition (80.8\%), Van Gogh Inside (83.8\%), and Drawn by the wind (96.7\%). Among the informative type of hashtags, the exhibition title was very frequent. Our finding indicated that if the exhibition place was located nearby shopping malls, train stations, or other landmarks - as it happened for Van Gogh Inside and Drawn by the wind - local information hashtags were more frequent (e.g. \#dongdaemundesignplaza and \#seoulstation). The art related hashtags exceeded $20 \%$ in all exhibitions and this type of information was the most frequent for Monet's Impressionism Exhibition. Except in the case of Monet's Impressionism Exhibition, the sum of exhibition venue and local information was higher than that of exhibition title or art general.

More generally, taking pictures in hang-out venues is one of the most popular habits among young Koreans. As people living in different continents and visiting museums in various countries, we can report that this is a behavior more widespread in Korea than in Western countries. As such, it has to be taken into account when interpreting results regarding the use of exposure hashtags or pictures of people.

\section{RESEARCH DESIGN AND IMPLEMENTATION}

The goal of this study is to understand what visitors share with other people about their museum visits and to derive the meaning of Instagram posts in respect of visitor experiences. Therefore, the research questions orienting our investigation are: What types of photos do museum visitors usually post on Instagram? What hashtags do they use? Is there any difference in Instagram posts according to the type of museum (i.e. generic museums vs. art museums)? Are Instagram posts useful for reflecting on museum experiences and visitors' impressions and emotions during and after a visit? These questions can be addressed through an exploration of Instagram posts related to museums.

We used a combination of quantitative research methods: word frequency, natural language processing, and automated image recognition. To show what kind of insight can be drawn from large scale quantitative research, we present two different kinds of analysis: an analysis of the Instagram hashtags of museums (phase 1) and an analysis of the Instagram 
images of museums (phase 2). We used the '4K Stogram' software to get Instagram posts including images and hashtags - that used the eight museum hashtags (e.g. \#louvremuseum). Within forty days (September 22 - November 02, 2019), we gathered 10,000 images for each museum, corresponding to a different number of posts for each museum, since users can upload more than one image in the same post. Because of their Data Policy and privacy issues, the only data provided by Instagram are pictures, tags, and information about the location, whenever users choose to geolocalize their pictures. Therefore, it is not possible to make accurate associations between Instagram use and demographic data. Some general statistics are available, but it is hard to say what percentage of the total Instagram audience visits museums. Relevant information regards the fact that travel is the most pursued interest by Instagram users (45\%), discovering new services and products is a goal for $83 \%$ of users (Facebook IQ 2019), and the biggest share is between 18 and 34 years old (33\%), equally distributed between men and women (Kemp 2019).
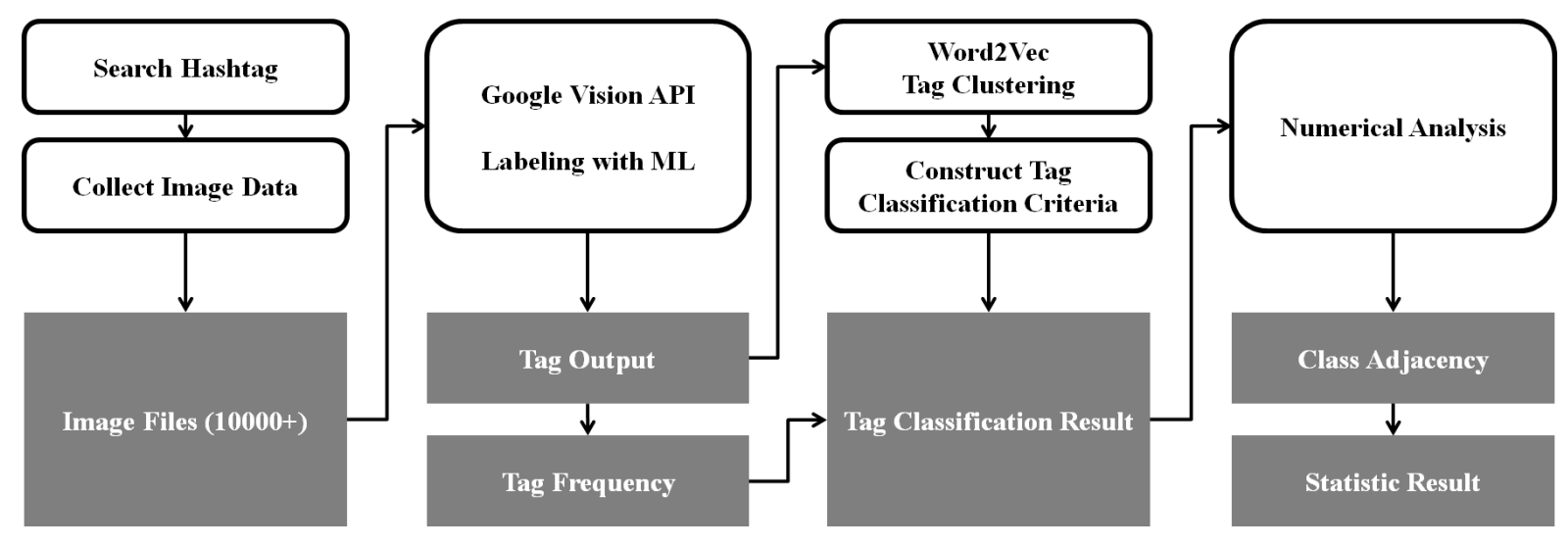

Figure 1

The Data Collection Process for Instagram Posts

\section{Phase 1. Analysis of museum-related Instagram hashtags}

\section{Methods}

In 2019, we started collecting the data of Instagram posts to examine the informational values of Instagram posts to understand museum experiences. We formulated the following research questions: Are museum-related hashtags used differently from exhibition-hashtags? Are hashtags used for generic museums different from those used for art museums? Can museum-related hashtags provide an insight into visitors' experiences? To explore our questions, we selected a total of four generic museums and four art museums from four different countries: Louvre Museum (hereafter LM) and Pompidou Center (hereafter PC) in Paris, France; Metropolitan Museum of Art (hereafter MET) and Museum of Modern Art (hereafter MoMA) in New York, USA; British Museum (hereafter BM) and Tate Modern (hereafter TM) in London, UK; National Museum of Korea (hereafter NMK) and Museum of Modern and Contemporary Art (hereafter MMCA) in Seoul, South Korea. Except the Korean museums, they were all listed as Most Instagrammed Museum 2016 (Davis 2016). According to the visitor statistics of Theme Index and Museum Index (2018), United States (31.6 million), United Kingdom (26.6 million) and France (10.2 million) present the highest museum attendance by nation. Except the Korean museums, six museums were highly ranked in both 2018/19 visitor figure published in the Art Newspaper and Wikipedia as well 
as the social media statistics summarized in the Art Newspaper and in Lazaridou et al. (2017). We also wanted to compare Western and Korean museums, so we included MK and MMCA, which have the greatest number of followers and posts on Instagram in Korea, although they are not listed in social media rankings (Table 1).

\section{Table 1}

Number of Visitors and Instagram Followers

\begin{tabular}{lcccc}
\hline \multirow{2}{*}{$\begin{array}{l}\text { Name of } \\
\text { Museum }\end{array}$} & \multicolumn{2}{c}{ Number of visitors (ranking) } & \multicolumn{2}{c}{ Number of Instagram followers (ranking) } \\
\cline { 2 - 5 } & 2019 & The Art Newspaper & Lazaridou et al. (2017) \\
\hline LM & $9,600,000(1)$ & $10,200,000(1)$ & $7,701,000(4)$ & $369,000(5)$ \\
PC & $3,273,867(22)$ & $3,551,544(14)$ & $5,456,646(7)$ & $22,000(22)$ \\
MET & $6,479,548(4)$ & $6,953,927(3)$ & $9,790,000(2)$ & $1,000,000(2)$ \\
MoMA & $1,999,121(31)$ & $2,744,103(20)$ & $12,442,000(1)$ & $1,200,000(1)$ \\
BM & $6,239,983(5)$ & $5,820,000(6)$ & $5,156,000(8)$ & $284,000(7)$ \\
TM & $6,098,340(6)$ & $5,868,562(5)$ & $9,312,000(3)$ & $486,000(4)$ \\
NMK & - & - & - & $3,776(29)$ \\
MMCA & - & - & - & -
\end{tabular}

In order to sample the same number of posts for each museum, from the original dataset we randomly selected 1,800 posts for each of them, which was the smallest number of posts available for a single museum in our dataset. After that, we removed the museum name hashtags, since we collected posts using them and, therefore, they are present in every post. However, we did not remove other spellings of the museums' name (e.g. \#louvre for \#louvremuseum), since redundancy in the use of hashtags related to the exhibition venue is a valuable information. Last, we manually categorized the hashtags appearing more than 50 times - that is, in at least $2.8 \%$ of the posts - and clustered them into informative, participatory, and exposure hashtags (Kim 2016; Oh et al. 2016; Rauschnabel et al. 2019; Park et al. 2019).

\section{Results}

The first notable finding is that Koreans tend to post a number of images per post that is double of what visitors of European and American museums usually do. And, on average, they also use a considerably lower number of hashtags per post (Table 2). 
Table 2

Summary of Visitors Posting Activity for 10,000 Images and Number of Hashtags for a Sample of Posts $(n=1800)$

\begin{tabular}{lcccc}
\hline $\begin{array}{c}\text { Name of } \\
\text { Museum }\end{array}$ & $\begin{array}{c}\text { Total number of } \\
\text { posts }\end{array}$ & $\begin{array}{c}\text { Average number of } \\
\text { images per post }\end{array}$ & $\begin{array}{c}\text { Total number of } \\
\text { hashtags }(\mathrm{n}=1800)\end{array}$ & $\begin{array}{c}\text { Average number of } \\
\text { hashtags per post } \\
(\mathrm{n}=1800)\end{array}$ \\
\hline LM & 4,106 & 2.4 & 14,358 & 8.0 \\
PC & 4,615 & 2.2 & 11,158 & 6.2 \\
MET & 3,366 & 3 & 10,554 & 5.9 \\
MoMA & 4,694 & 2.1 & 16,959 & 9.4 \\
BM & 3,231 & 3.1 & 11,019 & 6.1 \\
TM & 3,693 & 2.7 & 11,035 & 6.1 \\
NMK & 2,010 & 5 & 6,672 & 3.7 \\
MMCA & 1,848 & 5.4 & 7,599 & 4.2 \\
\hline
\end{tabular}

The results showed that for the LM and MoMA visitors frequently used a larger number of hashtags compared to other museums, however, the reasons are different. For the LM the name of the city is by far the most used hashtag (\#paris, $72 \%$ of the posts), whereas for the MoMA it is due to the great variety and frequency of art related hashtags, which are the top 11 hashtags - "\#newyork" is the $12^{\text {th }}$ most used occurring only in $9.7 \%$ of the posts.

On the other hand, the NMK had the smallest number of hashtags. Notably, it was visited by many people to see a show performed in one of the onsite facilities (i.e. Theater Dragon) - "\#musical" and "\#theatre" are the $5^{\text {th }}$ and $6^{\text {th }}$ most frequent hashtags, and the tile of the show is the first ("\#sejong1446") - a circumstance that also explains the high number of exposure hashtag (Table 3), together with Koreans' fondness for selfies, because this kind of audience is probably less interested in museum exhibitions and more accustomed to use Instagram for other purposes. For the MMCA, the English acronym \#MMCA was the most frequently used hashtag, highlighting a redundancy in the use of exhibition venue hashtags.

\section{Table 3}

Result of the Categorization of Instagram Hashtags

\begin{tabular}{|c|c|c|c|c|c|c|}
\hline \multirow[b]{2}{*}{$\begin{array}{l}\text { Name of } \\
\text { museum }\end{array}$} & \multicolumn{3}{|c|}{ Informative type } & \multirow[b]{2}{*}{$\begin{array}{l}\text { Exposure } \\
\text { type }(\%)\end{array}$} & \multirow{2}{*}{$\begin{array}{c}\text { Total occurrences } \\
\text { of hashtags used } \\
50+\text { times }\end{array}$} & \multirow[b]{2}{*}{$\begin{array}{l}\text { Most used } \\
\text { hashtag (n) }\end{array}$} \\
\hline & $\begin{array}{l}\text { Exhibition } \\
\text { venue (\%) }\end{array}$ & $\begin{array}{c}\text { Local } \\
\text { information } \\
(\%)\end{array}$ & $\begin{array}{c}\text { Art } \\
\text { General (\%) }\end{array}$ & & & \\
\hline $\mathrm{LM}$ & 25.6 & 40.2 & 18.0 & 16.2 & 7,722 & \#paris $(1,296)$ \\
\hline PC & 12.1 & 33.7 & 51.0 & 3.20 & 4,724 & $\#$ paris (857) \\
\hline MET & 29.1 & 38.7 & 28.1 & 4.10 & 4,982 & \#nyc (581) \\
\hline MoMA & 8.70 & 13.9 & 71.4 & 6.00 & 8,642 & \#art (611) \\
\hline $\mathrm{BM}$ & 10.9 & 38.6 & 39.6 & 10.9 & 4,363 & \#london (90) \\
\hline TM & 16.9 & 29.3 & 51.0 & 2.80 & 4,507 & \#london (751) \\
\hline
\end{tabular}




\begin{tabular}{lllllll} 
NMK & 16.8 & 25.1 & 37.7 & 20.4 & 1,997 & $\begin{array}{c}\text { \#sejong1446 } \\
(173)\end{array}$ \\
MMCA & 29.1 & 21.7 & 37.0 & 12.2 & 3,267 & \#mmca (382) \\
\hline
\end{tabular}

Overall, the most prominent type of hashtag was the informative type for all museums. In most cases, the sum of exhibition venue and local information was around $50 \%$ of the total number of hashtags used. The LM and the NMK had the highest number of exposure hashtags - way above the other museums - while TM had the lowest. The LM also had the smallest number of art-related hashtags, whereas they were more than $70 \%$ of the hashtags used for the MoMA. Generally, there seems to be a consistent ranking of the informative type of hashtags (art general $>$ local information $>$ exhibition venue), with the exception of the LM and the MET, because of the low number of art related hashtags. For the MMCA, the exhibition venue is more frequent than local information because the name of the museum is used both in Korean and English.

Compared to the study that analyzed the hashtags of Korean exhibitions, artists' names were rarely used in the sample of Western museums: we only found three names: \#francisbacon (PC), \#picasso (MoMA), and \#olafureliasson (TM). Rather, the terms of art movements (e.g. \#abstract art, \#abstractexpressionism, and \#popart) appeared frequently for art museums. However, when the artist's name was included in the title of the exhibition the name frequently appeared in hashtags: \#sounguikim, \#asgerjorn and \#parkseobo (MMCA), a result consistent with the study of Korean exhibitions' hahstags. It is also notable that artifacts' names were rarely used: we found only one occurrence, \#monalisa (LM, 7.2\%). In the case of the Korean museums, exhibition titles were quite frequent compared to other museums: \#etruscansexhibition, \#theetruscansrisingtorome, and \#throughtheeyesofjoseonpainters (23.1\%, NMK), and \#parkseoboexhibition, \#theuntiringendeavorer, \#asgerjorn, \#thesquare, and \#lazyclouds (28.4\%, MMCA).

\section{Phase 2. Analysis of museum-related Instagram images}

\section{Methods}

We categorized the images collected using the following method (cf. Figure 1). First, we employed computer vision techniques through the Google Vision API. We selected this tool because it offers excellent performance, it is quite simple, and well documented, so museums can set it up for their own analyses without much effort. Currently it can be used for free as a cloud computing service for the analysis of 1,000 images per month and it can easily retrieve the images to be analyzed from a Google Drive folder. The computer vision task consisted in object recognition performed by a pre-trained AI algorithm that returned at most ten labels for each image, for instance 'Pyramid', 'Illustration', 'Person', etc. (Fig. 2 ). The labels correspond to categories that the algorithm learned from previous training done by Google and have a confidence score and a topicality score, indicating the reliability of the object recognition and the object's contextual importance within in the image. We used all the returned labels, without filtering them, but museums could set lower limits to these scores in order to narrow down their analyses. 

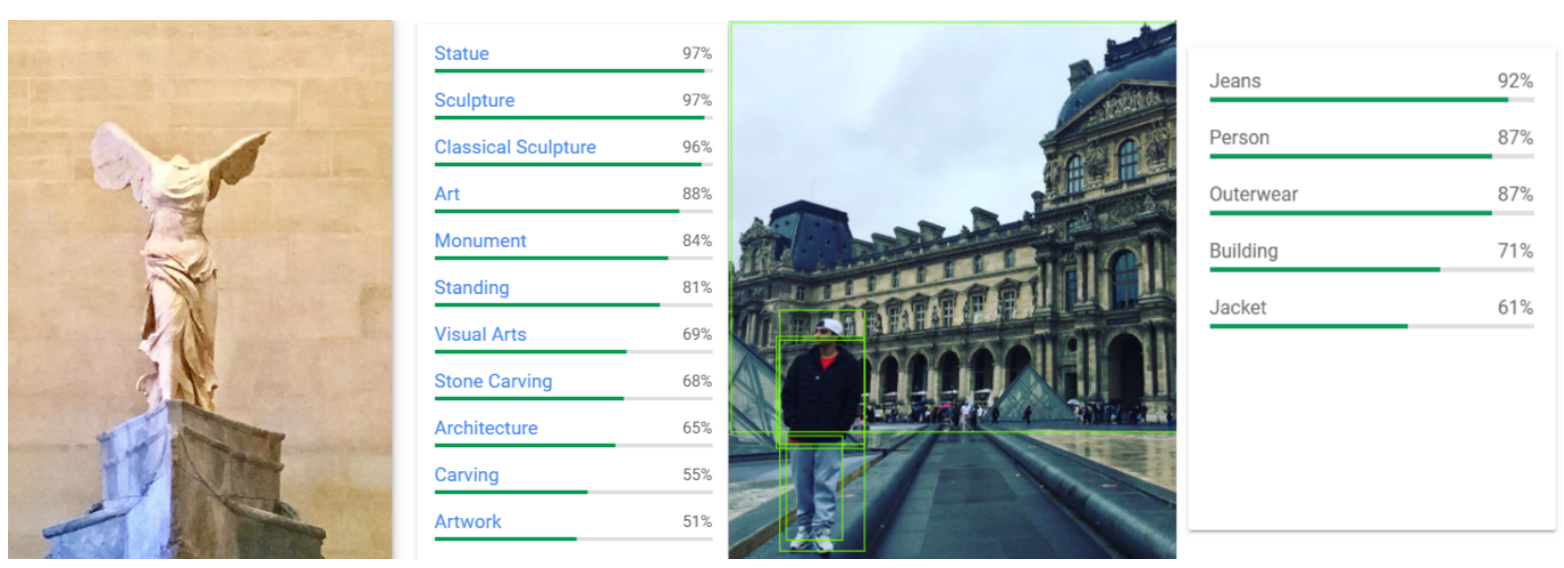

Figure 2

\section{Example of an Image Labelled Using Google Vision API's Object Recognition Feature}

Second, we trained a machine learning algorithm (i.e. word2vec) on all image labels to compute their semantic similarity. Word2vec is a model that produces a multidimensional vector space, in which each unique label in the dataset is assigned a corresponding vector. Label vectors are positioned in the vector space so that labels that frequently appear together in an image are located close to one another. Looking at the reduced two-dimensional output we then identified clusters of similar labels, which correspond to similar contents in the images: body, food, clothes, music, nature, interior, architecture, museum, animals, sport. Third, we edited these data-driven categories and combined them with top-down art categories relevant for our research, creating the following final list of image types: art exhibition (e.g. performances, events, and graphics), artifact (e.g. sculptures, paintings, and pottery), architecture (e.g. buildings, or parts of them, and indoor spaces), selfie (e.g. faces), food, human body (e.g. non-face body parts and people), landscape (e.g. outdoor spaces and nature).

Fourth, in order to maximize the number of labels retrieved for each of the categories for each museum, we trained word2vec models separately on the labels' subsets of each museum and retrieved the 50 most similar labels for each category. We then manually checked all lists to make sure that they include only tags relevant for the respective categories, to resolve overlaps between categories, and to delete ambiguous labels. Fifth, we replaced all labels in the dataset with each corresponding category, eliminating labels that did not belong to any of them. Sixth, we proceeded to do frequency and co-occurrence analysis, i.e. the presence in the images of one or more labels per category.

There are some limitations in using pre-trained AI methods: the labels are not accurate enough to classify objects and spaces related to art and museums. We used a tool that is available for free so that museums could learn to employ our methods and apply them to their data. For this purpose, we created a list of the labels used by Google Vision API that museums can reuse for their classification tasks (Rhee, Pianzola, and Choi 2020). Once a museum has collected the Instagram images and used the Google Vision API cloud computing service for object identification, our list can be used to group the various labels into categories relevant for museums and analyze the behavior of the museum's visitors on Instagram. 
Results

On average, eight objects have been recognized in every image and most of the images received the maximum number of labels, ten (Table 4).

Table 4

Number of Labels Returned by Google Vision API for 10,000 Images for Each Museum

\begin{tabular}{lccc}
\hline $\begin{array}{c}\text { Name of } \\
\text { Museum }\end{array}$ & $\begin{array}{c}\text { Total number of } \\
\text { labels }\end{array}$ & Mean & Median \\
\hline LM & 93,841 & 9.3841 & 10 \\
PC & 83,180 & 8.318 & 10 \\
MET & 88,606 & 8.8606 & 10 \\
MoMA & 83,301 & 8.3301 & 10 \\
BM & 86,728 & 8.6728 & 10 \\
TM & 84,102 & 8.4102 & 10 \\
NMK & 79,818 & 7.9818 & 10 \\
MMCA & 81,811 & 8.1811 & 10 \\
\hline
\end{tabular}

The results of the frequency analysis (Figure 3) show a marked difference between the kind of pictures taken in generic museums and art museums. In the former, visitors mostly take pictures of artifacts, in the latter they take pictures of the museum space. Of course, part of this difference is due to the different kind of art exhibited in the two types of museums, but art museums have many paintings, which are categorized as "artifact," however, visitors do not take many pictures of them. A second remarkable result regards pictures of buildings: the MoMA has a low number of architecture related pictures, perhaps because it has a less visually impactful architecture and interior design compared to other museums. For the BM, the popularity of the architecture category can be due both to the iconic façade and lobby, and to the great number of ruins there preserved. For the LM, it is certainly for the high number of pictures with the landmark pyramid, a result consistent with previous research on the official Instagram posts of LM and MET (Zingone 2019) (Figure 4). 


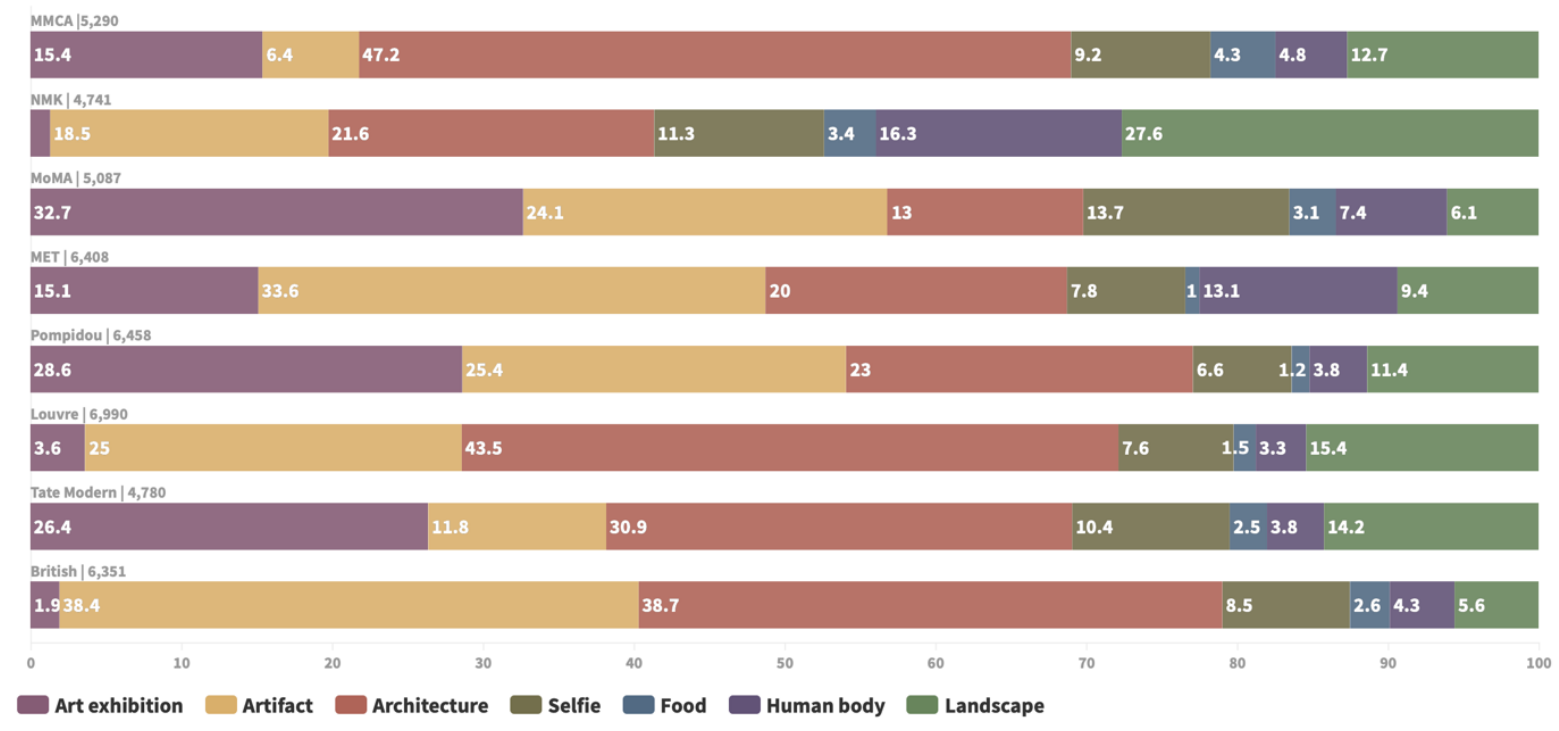

\section{Figure 3}

Total Number of Categorized Pictures and Ratio (\%) for Each Category for all the Eight Museums

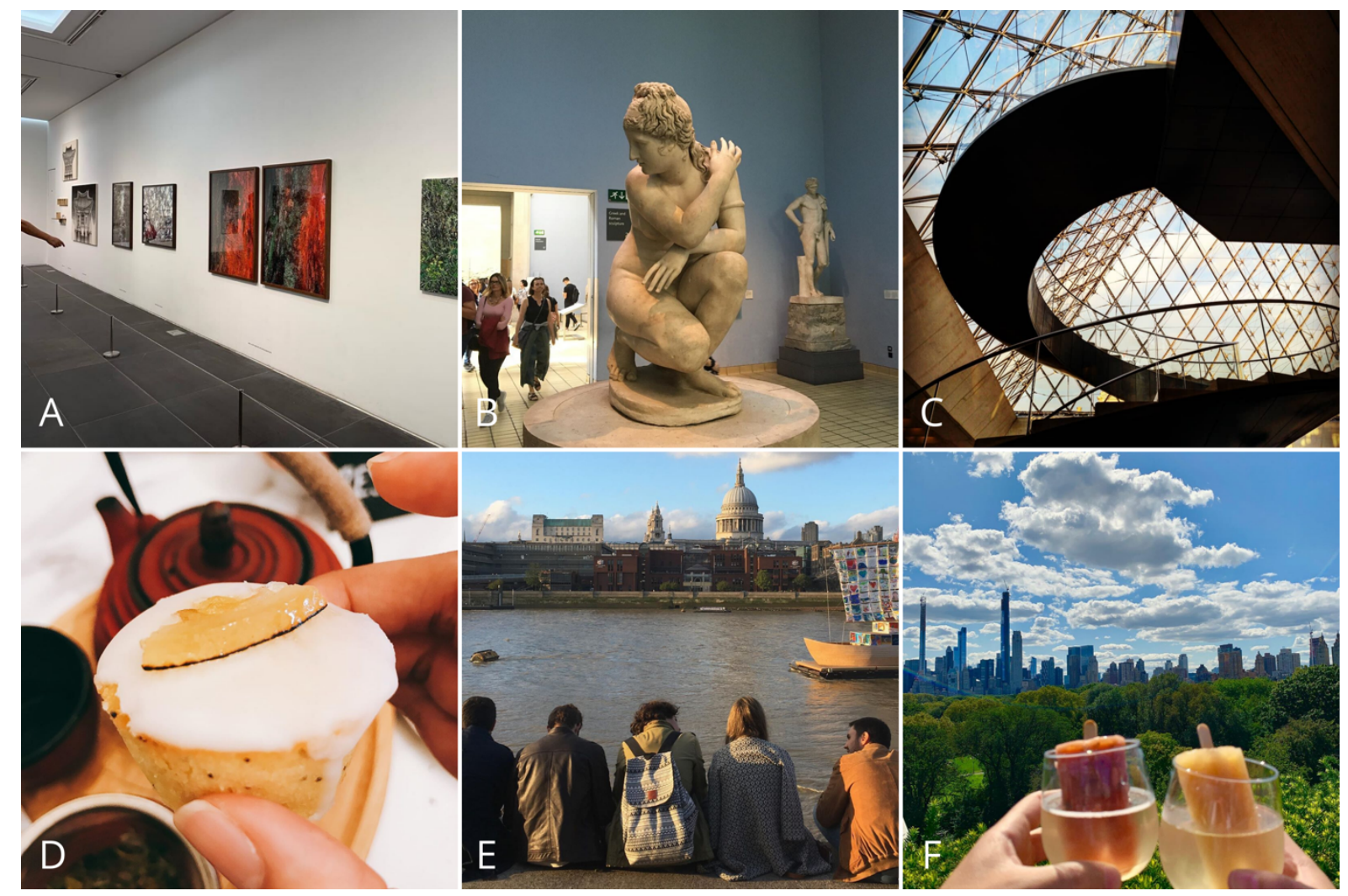

Figure 4

Example of Pictures for Each of the Categories: (A) Art Exhibition, (B) Artifact, (C) Architecture, (D) Food, (E) Human Body, (F) Landscape (Selfie Has Been Omitted for Privacy Reasons) 
Except MMCA and LM, the sum of art exhibition and artifact images is larger than that of architecture images: the dominance of architecture pictures for the MMCA is due to the large number of visitors who captured the spaces inside the museum together with art installations, which are often integrated with the architecture of the museum. In the case of LM, the palace overwhelmingly caught the eye of visitors. The sum of art exhibition and artifact images is also larger than that of selfies and people, a result consistent with previous research (Budge and Burness 2018; Budge 2017; Villaespesa and Wowkowych 2020). On the other hand, data show that NMK visitors take pictures of landscapes and other people more often than in other museums. The reason is the presence of vast quiet outdoor spaces surrounding the museum, which is situated nearby an artificial lake called Mirror Pond, making it an attractive location for photo shooting.

To sum up, visitors engage with objects rather than taking selfies. The average percentage for the artifact category was higher for art museums $(25.8 \%)$ than for generic museums (19.9\%). Except the MMCA, the number of pictures of artifacts is higher than that of selfies or people's pictures. According to visitors' statistics, at the MMCA in Seoul Generation Z and Millennials represented 47\% of the total 2.76 million visitors in 2019 (Jeon 2020). This is actually lower than the MoMA, which reported that more than half of their visitors are aged 18-34 (Romeo 2016). The different behaviors of Korean visitors who are the majority of people visiting the MMCA - is due to the widely spread Korean trend of taking selfies and posting them on Instagram.

Regarding the most photographed category-pairs (Figure 5), it is hard to make generalization about the visitors" experience, but this form of "distant reading" of Instagram pictures can nevertheless offer some insights. The popularity of the category artifact/architecture suggests that there are not many close-ups of a specific detail of museum objects, unlike reported by previous research (Villaespesa and Wowkowych 2020). Rather, pictures represent artifacts within the space in which they are exhibited, perhaps affirming the institutional role of the museum in consecrating art. Similarly, the second most popular pair is architecture/landscape, suggesting that visitors take pictures of museums from outdoor to show their presence in a place devoted to art. This seems to be confirmed by the high number of selfies with elements of the most popular categories of each museum: artifact and architecture for the BM, art exhibition for the MoMA, artifact for the MET, architecture for the LM. Notably, Koreans show two specific behaviors: they prefer full body shots more than visitors of other museums and take more pictures of food (cf. also figure 3 above). 


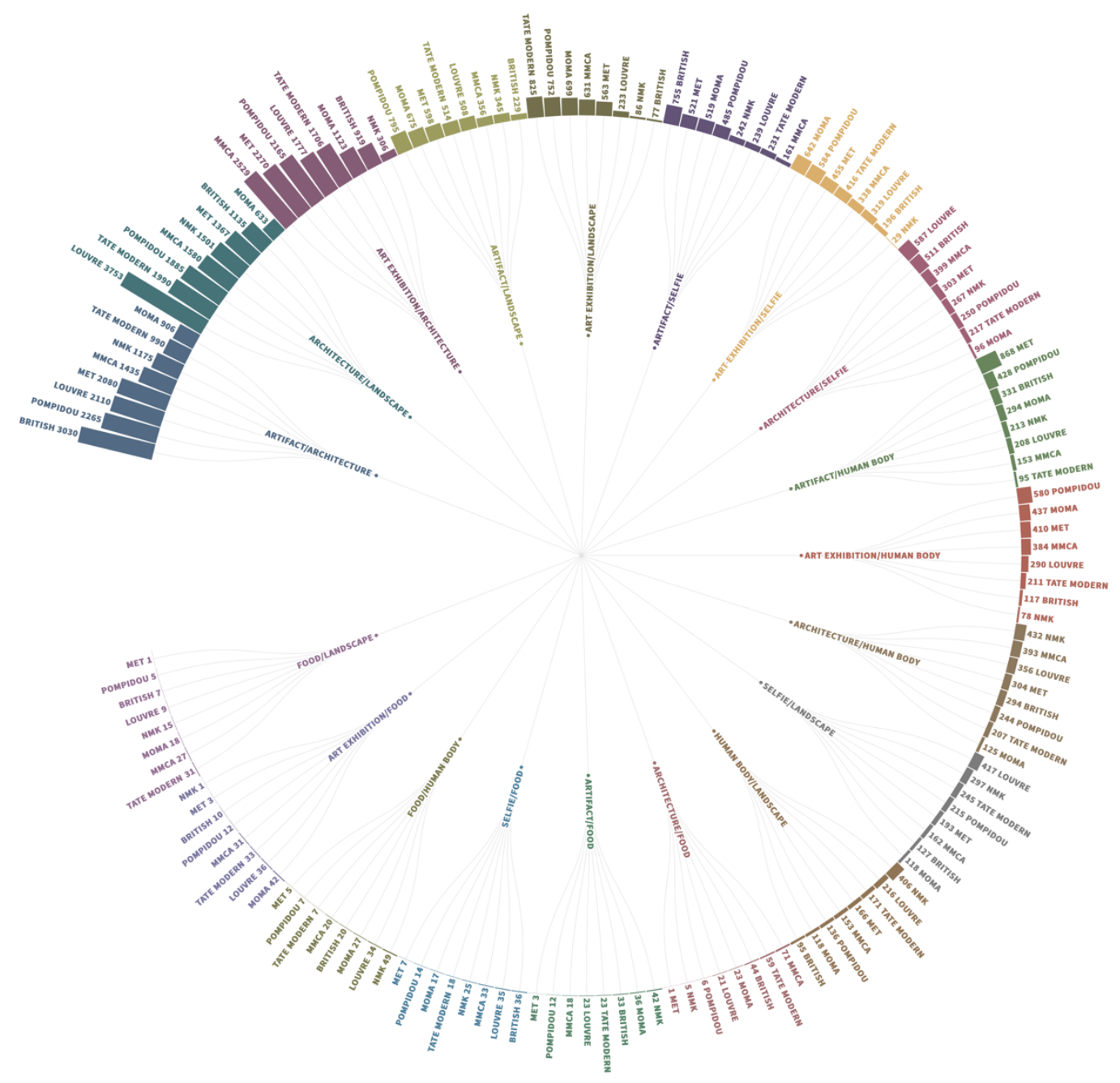

\section{Figure 5}

Number of Images for each Museum in Which There are Elements Belonging to Two Categories. Museums and Category-Pairs are Listed Clockwise in Descendent Order

\section{CONCLUSION}

This research examined visitors' hashtags and images of Instagram posts through a combination of quantitative methodology to cast light on museum experiences. The results of hashtag analyses showed that informative hashtags were the most prominent for all museums. It is notable that the geo-related hashtags such as exhibition venue and local information accounted for a significant portion of the total data, confirming previous research. The most used hashtags are heavily related to city names, a phenomenon due to the cultural and touristic power of the cities in which the analyzed museums are located. Images with place-making hashtags can allow other users to determine specific popular 
locations within a museum and enable museums to discover which spaces attracts visitors' attention the most.

Among the informative hashtag types, art related hashtags took up a significant proportion of the total data among art museums without any exception, a trend that we did not find in generic museums. The name of artist and exhibitions were rarely used for American and European museums but occurred frequently for Korean ones. Overall, little to no evidence of viewing experience or emotional response can be derived from the results of hashtag analysis. Instead, objective information related to the museums was predominant. Therefore, we can conclude that hashtags are not a very useful tool to gain insight about visitors' experiences. These results are consistent with previous research on memories of museum experiences: visitors do not share emotions "virtually" on the social networks (Kostoska et al. 2013).

In the image analysis of Instagram post, we found that different kind of pictures are posted for generic museums and art museums, due to the intrinsic differences of their collections. Among the image categories, art exhibition, artifact and architecture were dominant, but the space within and around museums is also relevant: work of arts are mostly photographed in the context in which they are exhibited, not focusing on details, and attractive venues are an incentive for visitors. Unlike the hashtag analyses of Instagram posts, the result of image analysis provides an understanding of visitors' experiences in museum environment. Thus, Instagram images can be an important component for understanding what is occurring within and around the museum when people move to take photographs and share these experiences on Instagram (Budge 2018, 109).

Based on our analysis, several insights about Instagram posts in relation to museum experiences are revealed: visitors engage with objects rather than taking selfies or people and at the same time, they involve in place-making and social presence processes rather than meaning-making for the exhibitions (Giaccardi and Palen 2008). Both visitors' experiences and discourses are anchored to physical places; remembrance of the museum experience via Instagram reaffirms the connection of body and mind in aesthetic processes. In other words, remembering and sharing exhibitions' experiences is closely related to one's embodied experience of that museum space (Hackett 2014). This is particularly true for Korean visitors - assuming they are the majority of visitors of Korean museums - who consider visiting the museum a memorable moment to be shared socially by taking a picture of themselves together with some art elements. Moreover, the visit is often included as part of a hang-out experience that also includes dining together and taking pictures of food.

Instagram posts also increase multiple voices and narratives around the museum objects and art exhibitions within a museum context. These posts and museum geolocations provide another avenue for discovering with which objects visitors are spending the most time and about what they want to learn more, thus, allowing museum professionals to create more useful, enjoyable, and relevant interpretive materials (Villaespesa and Wowkowych 2020).

A limitation of our study is that we did not investigate visitors' creative response to the museum visit, thus we do not know what discursive strategies are employed to elaborate the relation with artistic objects and venues. For instance, irony or in-group coded communications could have been employed to convey meanings and responses (e.g. irony) that cannot be inferred through the methods we employed.

Analyzing a large quantity of Instagram data was a challenging task and to further improve the quality of the automated categorization of images, we used computational tools like computer vision and semantic analysis in order to manage a bigger dataset and improve the reliability and accuracy of the results. Future research in this field of application of AI will 
benefit from improvement of image recognition algorithms, but nevertheless they will need to be fine-tuned on subsets of museum-related picture in order to be reliable and useful for the cultural sector.

By making art management and art technology converge we aimed at showing a new methodology for museum studies. This research offers to the museum community a new way to analyze data related to visitors and also provides an initial understanding of the type of hashtags and photos shared by visitors on Instagram. The usage of computer vision to classify Instagram images is an efficient solution for museums that would like to understand what their visitors express on social media on an ongoing basis. Previous research has been done in a manual way, which is not practical and realistic for the museum sector. The technology-based methods described in this paper can help to deepen the understanding of visitors' behavior and can be used for data-driven informed decision-making in museums, eventually creating new opportunities to develop programs that are more in tune to what visitors want.

We believe that the 4K Stogram software and the Google Vision API are relatively simple tools that can be used through a graphic user interface, therefore not requiring specific technical skills to gather relevant data. Once a dataset of interest is created and labelled, museums can then use the spreadsheets we made available and compare the returned labels with information pre-tested and refined on museum-relevant data. In this way, museums are able to perform a classification of Instagram posts in three simple steps.

Using AI, computer vision, and deep learning for visitor research is in its infancy. Even more, it is challenging for museum professionals, especially in small institutions with low budget and resources. By describing a relatively easy way to implement this kind of research and sharing open resources that can be used, transformed, and adapted by museums, we offer new opportunities for museums to learn more about their visitors.

\section{REFERENCES}

Budge, K. 2017. Objects in focus: Museum visitors and Instagram. Curator: The Museum Journal 60(1): 67-85.

Budge, K. 2018. Encountering people and place: Museums through the lens of Instagram. Australasian Journal of Popular Culture 7(1): 107-121.

Budge, K., and Burness, A. 2018. Museum objects and Instagram: agency and communication in digital engagement. Continuum 32(2): 137-150.

Capriotti, P., and Kuklinski, H. P. 2012. Assessing dialogic communication through the internet in Spanish museums. Public Relations Review 38(4): 619-626.

Carah, N. 2014. Curators of Databases: Circulating Images, Managing Attention and Making Value on Social Media. Media International Australia 150: 137-142.

Chlebus-Grudzień, P. 2018. Selfie at a museum: Defining a paradigm for an analysis of taking (self-portrait) photographs at museum exhibitions. Turyzm 28(1): 7-13. 
$\begin{array}{llll}\text { Collins } & \text { Dictionary, } & \text { accessed } & \text { January }\end{array}$ https://www.collinsdictionary.com/submission/21602/instagrammable

Conover, M. D., Ratkiewicz, J., Francisco, M., Gonçalves, B., Menczer, F., and Flammini, A. 2011. Political polarization on twitter. In Proceedings of Fifth international AAAI conference on weblogs and social media: 89-96.

Davidov, D., Tsur, O., and Rappoport, A. 2010. Enhanced sentiment learning using twitter hashtags and smileys. In Proceedings of the 23rd international conference on computational linguistics: posters, Association for Computational Linguistics: 241-249.

Davis, B. (December 1, 2016). Here are the world's most Instagrammed museums (global) of 2016, accessed January 24, 2020, https://news.artnet.com/art-world/most-instagrammedmuseums-2016-768923

Dawson, A. (March 31, 2020). Which museums have the biggest social media followings? The Art Newspaper, accessed June 16, 2020, https://www.theartnewspaper.com/analysis/museummasters-of-the-social-media-universe

Dudareva, N. 2014. Museums in social media, Museums and the Web 2014. accessed December 28, 2019 https://mwf2014.museumsandtheweb.com/paper/museums-in-socialmedia/

Facebook IQ. (February 6, 2019). How Instagram Boosts Brands and Drives Sales, accessed June 16, 2020, https://www.facebook.com/business/news/insights/how-instagram-boostsbrands-and-drives-sales

Facebook IQ. (February 14, 2019). How to Take Your Instagram Content to the Next Level, accessed June 16, 2020, https://www.facebook.com/business/news/insights/how-to-take-yourinstagram-content-to-the-next-level

Frosh, P. 2015. The Gestural Image: The Selfie, Photography Theory, and Kinesthetic Sociability. International Journal of Communication 9: 1607-1628. https://ijoc.org/index.php/ijoc/article/view/3146

Gelles, A. 2017. Putting the social in social media: interactive new media for museums. The $\begin{array}{lllll}\text { Museum } \quad \text { Review: } & \text { 2(1), accessed } & \text { January }\end{array}$ http://articles.themuseumreview.org/tmr_vol2no1_gelles

Giaccardi, E. and Palen, L. 2008. The Social Production of Heritage through Cross-media Interaction: Making Place for Place-making. International Journal of Heritage Studies 14(3): 281-297. 
Google Cloud Vision API, accessed September 22 through November 02, 2019 https://cloud.google.com/vision/

Hackett, A. 2014. Zigging and zooming all over the place: Young children's meaning making and movement in the museum. Journal of Early Childhood Literacy 14(1): 5-27.

Hasan, A., Moin, S., Karim, A., and Shamshirband, S. 2018. Machine learning-based sentiment analysis for twitter accounts. Mathematical and Computational Applications 23(1): 1-15.

Holdgaard, N., and Klastrup, L. 2014. Between control and creativity: challenging co-creation and social media use in a museum context. Digital Creativity 25(3): 190-202.

Ibba, S., Orrù, M., Pani, F. E., and Porru, S. 2015. Hashtag of Instagram: From Folksonomy to Complex Network. In Proceedings of KEOD 2015 - 7th International Conference on Knowledge Engineering and Ontology Development: 279-284.

Instagram Data Policy, accessed June 16, 2020, https://www.facebook.com/help/instagram/155833707900388

Jarreau, B., Dahmen P., Smith N., and Jones, E. 2019. Instagram and the science museum: a missed opportunity for public engagement. Journal of Science Communication 18(2): 1-22.

Jeon, Ji-Hyun. An art museum that emerged as a sacred art site for 20's (January 16, 2020). accessed February 20, 2020 https://www.mk.co.kr/news/culture/view/2020/01/55083

Kang, H. W., Park, S. W., Joo, Y. J., and Rhee, B. A. 2020. A study on sharing exhibition experience of Generation $\mathrm{Z}$ through Instagram posting [Unpublished paper].

Kelly, L. 2009. The impact of social media on museum practice. National Palace Museum, Taipei, 20, 1-14.

Kim, J. I. 2016. An investigation on the unexpected usages of hashtags in Instagram. Society of Design Convergence 15(2): 135-152.

Koke, J., and Ryan, K. 2017. From consultation to collaboration. In P. Villeneuve and A. R. Love (Eds.), Visitor-centered exhibitions and edu-curation in art museums (p. 47-55). Lanham: Rowman \& Littlefield.

Kostoska, G., Fezzi, D., Valeri, B., Baez, M., Casati, F., Caliari, S., and Tarter, S. 2013. Collecting memories of the museum experience. In CHI'13 Extended Abstracts on Human Factors in Computing Systems: 247-252. 
Kozinets R., Gretzel U., and Dinhopl A. 2017. Self in Art/Self As Art: Museum Selfies As Identity Work. Frontiers in Psychology 8(731). http://doi.org/10.3389/fpsyg.2017.00731

Lazaridou, Katerina, Vasiliki Vrana, and Dimitrios Paschaloudis. 2017. Museums + Instagram. In Vicky Katsoni, Amitabh Upadhya, and Anastasia Stratigea (eds.), Tourism, Culture and Heritage in a Smart Economy (p. 73-84). Cham: Springer.

McDonough, M. (December 5, 2017). Instagram's most popular cities, locations and hashtags $\begin{array}{llll}\text { of } 2917 . & \text { accessed } & \text { February } & 12,\end{array}$ https://www.washingtonpost.com/lifestyle/travel/instagrams-most-popular-cities-locationsand-hashtags-of-2017/2017/12/04/0461c772-d538-11e7-95bf-df7c19270879_story.html

Malik, M. N. 2019. A Theoretical Investigation into Instagram Hashtag Practices. Diss. Carleton University.

Oh, C., Lee, T., Kim, Y., Park, S., and Suh, B. 2016. Understanding Participatory Hashtag Practices on Instagram: A Case Study of Weekend Hashtag Project. In Proceedings of the 2016 CHI Conference Extended Abstracts on Human Factors in Computing Systems (CHI EA '16): $1280-1287$.

Omar, B. and Dequan, W. 2020. Watch, Share or Create: The Influence of Personality Traits and User Motivation on TikTok Mobile Video Usage. International Journal of Interactive Mobile Technologies 14(4): 121-137.

OMNICORE (Feb. 10, 2020). Instagram by the Numbers: Stats, Demographics \& Fun Facts. accessed February 12, 2020 https://www.omnicoreagency.com/instagram-statistics/

Park, J. J., Seok, A. Y., Yoon, Y. J., and Rhee, B. A. 2019. An Analysis of Instagram Hashtags Related to the Exhibitions in Korea. Journal of the Korea Society of Computer and Information 24(3): 49-56.

Păvăloaia, V. D., Teodor, E. M., Fotache, D., and Danileţ, M. 2019. Opinion Mining on Social Media Data: Sentiment Analysis of User Preferences. Sustainability 11(16): 4459. accessed February 12 , 2020 https://pdfs.semanticscholar.org/8ca5/358c7bdb0b80e87f89646d619015b5a238ce.pdf

Pett, D. 2012. Uses of social media within the British Museum and museum sector. Archaeology and digital communication: Towards strategies of public engagement: 83102.

Phan, K., and Melissa M. 2018. How Instagram is Changing the Art World." accessed February 12 , 2020. https://www.sccur.org/sccur/FALL_2018_CONFERENCE/SOC_SCI_POSTERS/82/ 
Pittman, M., and Reich, B. 2016. Social media and loneliness: Why an Instagram picture may be worth more than a thousand Twitter words. Computers in Human Behavior 62: 155-167.

Prensky M. 2001. Digital natives, digital immigrants. On the Horizon 9(5): 1-6.

Qadir, A., and Riloff, E. 2014. Learning emotion indicators from tweets: Hashtags, hashtag patterns and phrases. In Proceedings of the 2014 Conference on Empirical Methods in Natural Language Processing (EMNLP): 1203-1209.

Rauschnabel, P. A., Sheldon, P., and Herzfeldt, E. 2019. What motivates users to hashtag on social media? Psychology \& Marketing 36(5): 473-488.

Rhee, B. A. 2020. Museum 3.0 Era and Social Media. Seoul: Hangilsa.

Rhee, B. A., Pianzola, F., and Choi, G. T. (Mar. 10, 2020). Collection of categorized Google Vision API image tags for museums related pictures. Zenodo. http://doi.org/10.5281/zenodo.3706462

Russo, A., Watkins, J., and Groundwater-Smith, S. 2009. The impact of social media on informal learning in museums. Educational Media International 46(2): 153-166.

Sharpe, E. and S. Jose da (March 31, 2020). Art's most popular: here are 2019's most visited shows and museums, The Art Newspaper, accessed June 16, 2020, https:/www.theartnewspaper.com/analysis/art-s-most-popular-here-are-2019-s-most-visitedshows-and-museums

Sokolowsky, J. Art in the Instagram age: How social media is shaping art and how you experience it. The Seattle Times (November 16, 2017). accessed February 2, 2020 https://www.seattletimes.com/entertainment/visual-arts/art-in-the-instagram-age-how-socialmedia-is-shaping-art-and-how-you-experience-it/

Stylianou-Lambert, T. 2017. Photographing in the art museum: Visitor attitudes and motivations, Visitor Studies 20(2): 114-137.

Suess, A. 2014. Art gallery visitors and Instagram. Masters diss., University of Arts London. accessed $\quad$ February 11,2020 https://www. academia. edu/12086365/Art_Gallery_Visitors_and_Instagram.

Suess, A. 2018. Instagram and Art Gallery Visitors: Aesthetic experience, space, sharing and implications for educators. Australian art education 39(1): 107-122. 
Syed, A. Z. 2015. Applying sentiment and emotion analysis on brand tweets for digital marketing. In 2015 IEEE Jordan Conference on Applied Electrical Engineering and Computing Technologies (AEECT): 1-6.

Tartir, S., and Abdul-Nabi, I. 2017. Semantic sentiment analysis in Arabic social media. Journal of King Saud University-Computer and Information Sciences 29(2): 229-233.

TEA/AECOM. 2018. Theme Index and Museum Index 2018: Global attraction attendance $\begin{array}{llll}\text { report. } & \text { accessed June } & \text { 2020, }\end{array}$ http://www.teaconnect.org/images/files/TEA_328_381804_190528.pdf

The Art Newspaper, Exhibition and museum visitor figure 2018: Top 10 most popular art museums, accessed September 13, 2019, https://www.theartnewspaper.com/news/art-s-mostpopular-exhibition-and-museum-visitor-figures-2018.

The International Council of Museums. 2019. Social Media Guidelines for ICOM Committees. Paris: The International Council of Museums. accessed February 20, 2020 https://icom.museum/wp-content/uploads/2019/10/ICOMSocial-media-guidelinesWeb.pdf

Villaespesa, E. 2013. Diving into the museum's social media stream. Analysis of the visitor experience in 140 characters. Museums and the Web 2013. accessed December 23, 2019 https://mw2013.museumsandtheweb.com/paper/diving-into-the-museums-social-mediastream/

Villaespesa, E., and Tate, U. K. 2015. An evaluation framework for success: Capture and measure your social-media strategy using the Balanced Scorecard. Museums and the Web 2015. accessed December 23, $2019 \mathrm{https}: / / \mathrm{mw} 2015$.museumsandtheweb.com/paper/an-evaluationframework-for-success-capture-and-measure-your-social-media-strategy-using-the-balancedscorecard/

Villaespesa, E., and Wowkowych, S. 2020. Ephemeral Storytelling with Social Media: Snapchat and Instagram Stories at the Brooklyn Museum. Social Media + Society 6(1), accessed February 23, 2020 https://journals.sagepub.com/doi/pdf/10.1177/2056305119898776

Weilenmann, A., Hillman, T., and Jungselius, B. 2013. Instagram at the museum: communicating the museum experience through social photo sharing. In Proceedings of the SIGCHI conference on Human factors in computing systems: 1843-1852.

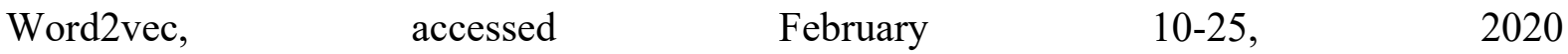
https://radimrehurek.com/gensim/models/word2vec.html\#module-gensim.models.word2vec Zafiropoulos, K., Vrana, V., and Antoniadis, K. 2015. Use of twitter and Facebook by top European museums, Munich Personal RePEc Archive (MPRA): 16-25. 
Zingone, M. 2019. Instagram as Digital Communication Tool for the Museums: a Reflection on Prospectives and Opportunities through the Analysis of the Profiles of Louvre Museum and Metropolitan Museum of New York. European Journal of Social Science Education and Research 6(3): 53-63. 